\title{
Língua e cultura no curso de graduação em Letras: uma reflexão sobre as concepções de alunos, Projeto Político Pedagógico e programas de ensino
}

\author{
Ana Cristina Biondo Salomão \\ Universidade Estadual Paulista "Júlio de Mesquita Filho" (UNESP) \\ Araraquara, São Paulo, Brasil \\ ana.salomao@fclar.unesp.br
}

DOI: http://dx.doi.org/10.21165/el.v45i2.684

\begin{abstract}
Resumo
Este artigo apresenta os resultados de uma pesquisa qualitativa e quantitativa que visou investigar as concepções de cultura de alunos de graduação em Letras-inglês de uma universidade pública do interior do estado de São Paulo, relacionando-as às concepções de cultura presentes no Projeto Político Pedagógico e nos programas de ensino de língua inglesa do referido curso. Os resultados mostram a necessidade de se problematizar o foco em identidades nacionais por meio de conceitos-chave, como competência intercultural, competência simbólica, essencialismo cultural e alteridade, entre outros, na base de conhecimentos do curso de graduação em Letras. Desse modo, o curso poderá mais bem atender às demandas criadas para a educação de línguas na contemporaneidade, com a expansão da mobilidade e comunicação atuais como transformadoras da realidade local.
\end{abstract}

Palavras-chave: educação linguística; graduação em Letras; cultura.

Language and culture in the undergraduate course in Language and Literature: a reflection upon the conceptions of students, Pedagogical Political Project and teaching programs

\begin{abstract}
This article presents the results of a qualitative and quantitative research that aimed to investigate culture conceptions from undergraduate students of English Language and Literature of a public university of the countryside of São Paulo state, relating such culture conceptions to the ones present in the Pedagogical Political Project and in teaching programs of English language of the referred course. The results show the need to question the focus on national identities by means of key concepts, such as intercultural competence, symbolic competence, cultural essentialism, and otherness, among others, on the knowledge base of the undergraduate course of Languages and Literature. Thus, the course will be better able to meet the demands created for language education in contemporary times, with the expansion of current mobility and communication as transforming agents of local reality.
\end{abstract}

Keywords: linguistic education; undergraduate degree in Language and Literature; culture. 


\section{Introdução}

A língua inglesa tem ganhado cada vez mais importância como instrumento de comunicação intercultural devido à expansão das ferramentas de comunicação eletrônica na internet e da possibilidade de mobilidade de profissionais e de estudantes. Autores contemporâneos, como Risager (2007), Kramsch (2009; 2011a,b), Salomão (2011; 2015), Dervin e Liddicoat (2013), criticam o foco em identidades nacionais ao tratar o componente cultural no ensino e aprendizagem de línguas e apontam para o professor como importante agente na orquestração da interação de várias histórias de vida e horizontes de entendimento, o que traz à tona a necessidade de se repensar os recursos linguísticos dos aprendizes, a relação entre língua e cultura e o conceito de cultura que permeia as práticas educativas na área.

De acordo com Kramsch (2011b), uma vez que a Linguística Aplicada emergiu em um período de ideologias nacionais e consciência étnica, a concepção de cultura primeiramente nela encontrada era essencialista, voltada a características nacionais ou de grupos étnicos. Após a Segunda Guerra Mundial, linguistas aplicados tendiam a equacionar um sistema linguístico padrão a uma cultura padrão. Tanto língua como cultura seriam então vivenciadas e faladas por seus falantes nativos, vistos como uma comunidade nacional um tanto quanto homogênea com suas instituições, costumes e modo de vida de longa data. Entretanto, segundo a autora, a virada social na Linguística Aplicada trouxe à frente um vigoroso interesse no estudo do componente social no ensino de línguas baseado em uma variedade de domínio de pesquisa relacionado à discurso, análise da conversação, pragmática transcultural, comunicação e aprendizagem intercultural.

Acreditamos que essa mudança de perspectiva veio ao encontro das necessidades da realidade que vivemos hoje com a expansão das novas tecnologias da comunicação e com as migrações globais, mas pensamos que ela está muito mais desenvolvida na teoria. Muitas das práticas docentes ainda enfocam cultura como informação sobre o outro, baseadas em uma visão de cultura nacional geograficamente delimitada (SALOMÃO, 2011; 2012). Nesse sentido, o curso de graduação em Letras carece de um olhar mais profundo sobre a formação do profissional/futuro professor a fim de incorporar meios para a promoção da reflexão sobre temáticas de ordem cultural, adentrando questões relacionadas à identidade e à representação do outro. Discutimos, nesse artigo, resultados de uma pesquisa qualitativa que visou investigar as concepções de cultura de alunos de graduação em Letras-inglês de uma universidade pública do interior do estado de São Paulo, relacionando-as às concepções de cultura presentes no Projeto Político Pedagógico do curso de Letras e nos programas de ensino de língua inglesa.

Nossa intenção é contribuir com reflexões sobre o que deve figurar na base de conhecimentos do curso de graduação em Letras no que tange ao conceito de cultura na educação linguística na atualidade, a fim de que os futuros professores estejam preparados para romper com visões homogeneizantes e essencialistas de cultura e com o foco do ensino em típicos, e às vezes estereotipados, comportamentos, comidas, festas e costumes do grupo dominante ou daquele grupo de falantes nativos que é o mais saliente ou exótico aos olhos estrangeiros. Entender cultura como híbrida, em movimento, dinâmica, fluida e variável na relação interpessoal, a nosso ver, viria ao encontro das necessidades de comunicação 
intercultural no mundo contemporâneo, mas para isso o primeiro passo a ser dado deve ser o de uma mudança epistemológica no que tange à visão de cultura na formação (inicial e continuada) de professores de línguas na atualidade.

\section{$O$ conceito de cultura}

Segundo Dervin e Liddicoat (2013), a educação intercultural tem se rendido ao conceito de cultura como uma entidade fixa e estática, ignorando os desenvolvimentos do entendimento de cultura como dinâmica e contraditória na contemporaneidade. De fato, cultura é uma palavra que traz em seu bojo imensa complexidade. Nosso percurso nessa seção busca percorrer de forma sucinta o desdobramento de tal conceito desde o latim até os dias atuais para então discutir o modo como ela é entendida no ensino de línguas na contemporaneidade ${ }^{1}$.

Ao desdobrar-se semanticamente de cultivo, em sua derivação do latim, cultura passa a denotar questões que vão além da lavoura, como o conhecimento produzido pela humanidade (CUCHE, 2002). Ao perpassar as ideias do Iluminismo, com ênfase nos ideais de progresso, foi entendida como o conhecimento racional e livre exercício das capacidades humanas, partindo de uma concepção universalista, que considerava cultura como uma totalidade de traços que caracterizavam a vida coletiva. A partir dos estudos da antropologia nos séculos XVIII e XIX, cultura passa a ser vista por meio de perspectivas particularistas, que buscavam entender "as culturas" e não somente a "Cultura", baseando-se em perspectivas etnográficas.

Embora haja um avanço ao buscar compreender cultura como construção social, distanciando de visões inatistas, nota-se, ainda, a visão calcada em teorias evolucionistas e deterministas, que permeavam o pensamento científico da época. Assim, todas as sociedades se moveriam em direção ao mesmo objetivo evolutivo, em diferentes velocidades. Tratava-se de uma concepção hierárquica de cultura, na qual o eurocentrismo determinava o patamar a ser atingido.

Com os estudos sobre aculturação no século XX, cultura passou também a ser entendida com um conjunto complexo e dinâmico, que, devido ao fato universal dos contatos culturais, é formada, em diferentes graus, por culturas 'mistas' (e não mais 'puras' e 'mestiças'), feitas de continuidades e de descontinuidades, e, com a etnografia interpretativista de Clifford Geertz, ela também passou a denotar um domínio de comunicação simbólica, que nos permite analisar o fluxo do discurso social.

Ainda, é importante lembrar que o foco da antropologia a partir da década seguinte, 1980, por influência dos Estudos Culturais, passou a se voltar também para os estudos das complexas sociedades modernas ao invés de se focar estritamente em sociedades pequenas e menos complexas socialmente, o que traz importantes elementos para o desenvolvimento da pedagogia de ensino de línguas envolto nas relações culturais e sociais das sociedades contemporâneas (RISAGER, 2006).

\footnotetext{
${ }^{1}$ Para uma discussão mais aprofundada sobre a questão ver Salomão (2015).
} 
Nesse sentido, Hall (2006) discute a identidade cultural do indivíduo na atualidade apontando para a fragmentação e a "descentração" do sujeito pós-moderno, que "assume identidades diferentes em diferentes momentos, que não são unificadas ao redor de um 'eu' coerente" (p.13). O autor afirma:

A sociedade não é, como os sociólogos pensaram muitas vezes, um todo unificado e bem delimitado, uma totalidade, produzindo-se através de mudanças evolucionárias a partir de si mesma, como o desenvolvimento de uma flor a partir de seu bulbo. Ela está constantemente sendo "descentrada" ou deslocada por forças fora de si mesma. (HALL, 2006, p. 17)

Assim, a concepção essencialista ou fixa de identidade cultural do sujeito moderno estritamente atrelada ao estado-nação já não é capaz de explicar quem somos em um mundo no qual características temporais e espaciais se comprimiram e a cultura nacional é vista como discurso. Na mesma linha, Bauman (2013) aponta para um mundo líquido, no qual a cultura, antes "enfática, severa e inflexível" (p. 11), agora "consiste em ofertas, e não em proibições; em proposições, não em normas" (p.18). Concordamos com o autor que nesse momento a cultura se manifesta em forma de produtos a serem consumidos, e entendemos como Hall (2006) a incerteza que vivemos, que abala nossos quadros de referência, afetando profundamente a nossa relação com o próprio conhecimento.

Para o ensino de línguas, esse quadro teórico contemporâneo implica (re)pensar a relação entre língua e cultura, que não se pode servir a objetivos utilitaristas. Ela deve, antes, colocar-se na educação linguística como forma de autorreflexão, baseada em subjetividade e historicidade na construção da identidade cultural dos indivíduos.

\section{Relação entre língua e cul tura no ensino de línguas}

Risager (2007) traça um histórico da relação entre língua e cultura no ensino de línguas, enfocando as décadas de 1960 até o ano 2000. Para a autora, a história da pedagogia de ensino de cultura até a década de 60 foi amplamente baseada no conceito de "realia", que ela descreve como uma tradição puramente informativa de cultura, com 'coisas' ou artefatos da cultura alvo trazidos para o ensino em sala de aula, que poderiam ser textos na língua alvo, livros e objetos de viagem que trouxessem informações práticas sobre o lugar de destino. Ela afirma (p. 29):

Assim, parece como se certo consenso tivesse emergido entre os autores de livros didáticos desde o movimento de reforma no final do século XIX que o ensino de línguas, também no nível elementar, deveria ser acompanhado por uma coloração cultural que poderia levar a lidar com a vida no país do idioma de destino. (RISAGER, 2007, p. 29)

Segundo a autora, a partir da década de 1970, esforços foram feitos para que o ensino de cultura saísse de uma posição marginal e, coincidindo com a expansão do conceito de texto, foram introduzidos textos que não somente os literários no ensino de línguas, como: vários tipos de ficção, textos de revistas e jornais, menus, placas, entre outros. Foi ainda nessa década que se convencionou estabelecer a diferença entre Cultura com $\mathrm{C}$ maiúsculo e cultura com c minúsculo: a Cultura seriam os grandes feitos de um povo, que se refletem em 
sua história, instituições sociais, obras de arte, arquitetura, música e literatura, enquanto que a cultura abrangeria os costumes, tradições e práticas cotidianas das pessoas.

Para o ensino de línguas, tais visões, segundo Kramsch (2009, p. 221), implicam a promoção do Estado-nação e suas instituições:

Ensinar sobre a história, as instituições, a literatura e as artes do país-alvo incorpora a língua-alvo na reasseguradora continuidade de uma comunidade nacional que the dá sentido e valor. [...] $\mathrm{O}$ fato de que línguas estrangeiras ainda são ensinadas na maioria das vezes em departamentos de língua estrangeira e literatura e de que o currículo para graduandos em língua estrangeira ainda coloca uma grande ênfase no estudo da literatura é um lembrete de que o estudo de línguas foi originalmente subserviente aos interesses dos filólogos e estudiosos literários, não de antropólogos e sociólogos.

Nota-se que a autora atribui a visão de Cultura a uma tradição humanista que a conceitua como um produto de conhecimento literário e artístico canônico da 'cultivada' classe-média, que foi instrumental na construção do Estado-nação no século XIX. Sua crítica em relação à subserviência da aprendizagem de línguas à filologia e estudos literários demonstra novamente que o conceito de cultura geralmente esteve mais intimamente ligado à ideia de Cultura no ensino de línguas estrangeiras. Um exemplo disso é o Método Gramática e Tradução, que segundo Richards e Rodgers (1999), dominou o ensino e a aprendizagem de línguas de 1840 a 1950, tendo como objetivo principal a aprendizagem da língua estrangeira para a leitura de obras literárias na língua alvo a fim de prover "disciplina mental e desenvolvimento intelectual" (p. 3) do aprendiz.

Na década de 1980, o conceito antropológico de cultura se torna referência comum, trazendo também a ideia do ensino de línguas como uma tarefa intercultural, uma vez que a pedagogia de ensino de cultura passou também a se interessar no conhecimento trazido pelos alunos sobre seus próprios países, suas percepções de si mesmos e de sua identidade nacional. Segundo Risager (2007), poucos trabalhos, ainda, problematizavam a questão do paradigma nacional e o desenvolvimento das tecnologias de vídeo trouxe maiores oportunidades de se trabalhar com aspectos concretos e visíveis da língua, cultura e sociedade em questão. Ainda, nessa década, o casamento entre língua e cultura foi consumado em expressões como "língua-e-cultura" ("language-and-culture"), com muitos autores apontando para a indissociabilidade entre língua e cultura.

$\mathrm{Na}$ década de 1990, segundo Risager (2007), a pedagogia de ensino de línguas testemunhou uma virada cultural, que resultou, entre outras coisas, na criação de uma seção devotada ao componente cultural no ensino de línguas no congresso mundial de Linguística Aplicada (AILA) que ocorreu em Amsterdã, em 1993. De acordo com a autora, essa década foi bastante caracterizada pela internacionalização, com aumento da mobilidade de estudantes para aprender línguas no exterior, assim como a explosão das tecnologias da informação e comunicação, aumentando os contatos pessoais transnacionais, o que levou o ensino de línguas a se focar nos encontros culturais e na cultura experienciada pelo indivíduo. A relação entre língua e cultura continuou a ser vista como indissociável; entretanto, duas correntes surgiram: uma estruturalista, que enfocava a língua como sistema, e uma pós-estruturalista, que 
enfocava a língua como prática e clamava a inseparabilidade entre o evento linguístico e o contexto cultural.

Para Risager (2007), o início de 2000 continuou a tradição advinda da década de 1990, com uma expansão ainda maior de estudos, conferências, redes de pesquisa e cooperação internacional sobre a cultura e a comunicação intercultural. Maiores esforços vêm sendo feitos para problematizar o paradigma nacional no entendimento de cultura. Propostas de se trabalhar com a competência intercultural crítica (GUILHERME, 2014) e a cidadania intercultural (BYRAM, 2014) avançam nesse sentido ao propor que o trabalho com a interculturalidade vise a reflexões e ações do indivíduo sobre a vida em sociedade, saindo assim do plano individual e avançando para a coletividade, pautado em questões de cooperação solidária, agenciamento ativo e democracia social. Ainda, em um mundo no qual as interconexões se acentuaram devido ao aumento da mobilidade das pessoas, assim como pelo contato com outros por meio do uso das novas tecnologias da informação e comunicação, algumas propostas (KRAMSCH, 2009, 2011a,b) focam também em perspectivas discursivas e socioculturais (THORNE, 2006; KUMARAVADIVELU, 2008), ao compreender cultura como um processo constitutivo, construído na interação e no pragmatismo dos encontros interculturais.

Acreditamos que a prática de sala de aula ainda não se constitui como lócus dessa visão pós-moderna de cultura. Na seção a seguir, analisamos os dados coletados e discutimos a formação do professor de línguas na atualidade no que tange ao conceito de cultura.

\section{Metodologia de pesquisa}

Nossa investigação foi guiada pela seguinte pergunta de pesquisa: Quais são as concepções de cultura dos alunos de Letras-inglês e como elas se relacionam com as concepções de cultura que subjazem o Projeto Político Pedagógico do curso e os programas de ensino das disciplinas de língua inglesa?

Fizemos a opção por um desenho de pesquisa qualitativa e quantitativa - mixed methods research (DORNYEI, 2007), por meio de um questionário semiestruturado, no qual buscamos mapear tais concepções de acordo com o ano de graduação, histórias e experiências pessoais e influência das disciplinas do curso. Este questionário foi aplicado aos alunos do curso de Letras-inglês no primeiro semestre de 2014. As respostas dos alunos foram analisadas, buscando-se a articulação dos resultados encontrados nelas em relação àqueles encontrados no Projeto Político Pedagógico do referido curso e nos Programas de ensino de língua inglesa (tanto na grade atual como na nova, que ainda está em tramitação). Nosso intuito foi verificar em que medida o Projeto e os Programas se encontram alinhados no que tange às concepções de cultura e como eles se enquadram nas teorias atuais sobre cultura e ensino de línguas. Buscamos ainda entender de que modo as concepções dos alunos se relacionam ou não com as concepções subjacentes ao Projeto e aos Programas.

\section{Análise e discussão dos dados}


Primeiramente conduzimos a análise do questionário disponibilizado on-line por meio do software SurveyMonkey (<https $/ /$ pt.surveymonkey.com/>) e respondido por 100 alunos do curso de Letras-inglês, de $1^{\circ}$ ano a $4^{\circ}$ ano.

Ao questionarmos os alunos sobre a importância de se enfocar o conceito de cultura no curso de graduação em Letras, houve unanimidade em apontar para tal ação como essencial. Cremos que isso aponta para uma consciência de que o professor ou profissional de línguas estrangeiras é um importante agente na orquestração da interação de várias histórias de vida e horizontes de entendimento, e que, considerada em uma perspectiva global, a aprendizagem de línguas é hoje uma experiência institucionalizada que traz à tona fluxos culturais, discursivos e linguísticos que, sob dadas condições sociais, materiais e pedagógicas, podem se transformar e contribuir com os fluxos globais de significados (RISAGER, 2006).

Quadro 1: Respostas abertas dos alunos sobre a importância de se abordar cultura no curso de graduação em Letras segundo os alunos

Sem o conceito de cultura, em todas as suas abordagens, não seríamos nada, e não teríamos a oportunidade de aumentar nosso repertório. É muito importante.

É essencial, devido, justamente, a essa relação que há entre a língua e a cultura.

Acredito que em um curso onde a língua é o objeto de estudo, é fundamental o enfoque no conceito de cultura.

Extremamente importante, já que o conceito de cultura nos ajuda a compreender uma língua, assim como o conhecimento daquela língua nos ajuda a des vendar uma cultura diferente da nossa.

Mais do que me formar como um professor de determinada língua, quero me formar como um especialista de tudo que envolve essa língua.

Entende-se melhor a língua e a cultura de certo povo quando estudadas em conjunto.

Estudamos as mais diferentes literaturas e línguas; sem o enfoque na cultura, esse aprendizado será raso.

Es sencial, pelo fato de ser um curso tão abrangente, complexo e relacionado com as diferentes culturas de diferentes línguas

Essencial. Is so porque há um movimento muito grande sobre a interculturalidade se mostrando ótimo no desenvolvimento do ensino de línguas. Como já dito língua e cultura estão completamente ligadas, uma interferindo na outra. Sendo assim, quando uma aula de língua tem embasamento na cultura, o aluno se aproxima muito mais do idioma.

É essencial, pois não há como dis sociar língua de cultura, caso contrário, o estudante estará adaptando uma língua estrangeira aos costumes de sua língua materna.

Como podemos ver nas afirmações dos alunos, muitos deles interligam cultura e língua, que parece se assemelhar à visão mantida por Kramsch (1993, 1998), Agar (1994), entre outros, que tem influenciado o ensino de línguas nas últimas décadas, de que língua e cultura estão intimamente relacionados.

Para Risager (2007), uma distinção pode ser feita no ponto de partida para se tratar da relação entre língua e cultura no ensino de línguas, o que ela identifica por meio de dois modelos: o linguístico (culture-in-language - que insere a cultura na língua(gem)) e o das ciências sociais (language-in-culture - que insere a língua(gem) na cultura). Segundo a autora, os estudiosos que tiveram como ponto de partida o modelo linguístico para discutir questões de cultura geralmente utilizavam abordagens voltadas à comunicação, à pragmática, à semântica, à análise do discurso e à sociolinguística, enquanto que aqueles que partiram das 
ciências humanas ou sociais se baseavam em abordagens advindas da antropologia cultural, da psicologia, da sociologia, das ciências sociais e da pedagogia.

É possível notar, nas respostas abertas dos alunos no questionário, que suas visões parecem partir do modelo linguístico, o qual vê "cultura na língua(gem)" (culture-inlanguage). Tal constatação explica-se, a nosso ver, pelo fato de que ao estudarem Letras estão e/ou estiveram mais em contato com as teorias que Risager (2007) aponta como fonte de tal modelo (comunicação, pragmática, semântica, análise do discurso e sociolinguística). Concordamos com a autora que há que se problematizar a relação entre língua e cultura levando-se em conta também as complexas histórias de vida dos indivíduos, buscando-se no ensino de línguas uma perspectiva transnacional.

Os alunos foram ainda questionados sobre em quais disciplinas do curso de graduação notavam a temática cultura. Como opções de respostas, listamos todas as disciplinas de língua e literatura em língua inglesa. O quadro a seguir mostra o número de respostas para cada uma delas.

\section{Quadro 2: Disciplina de língua e literatura em língua inglesa e o foco em cultura segundo os alunos}

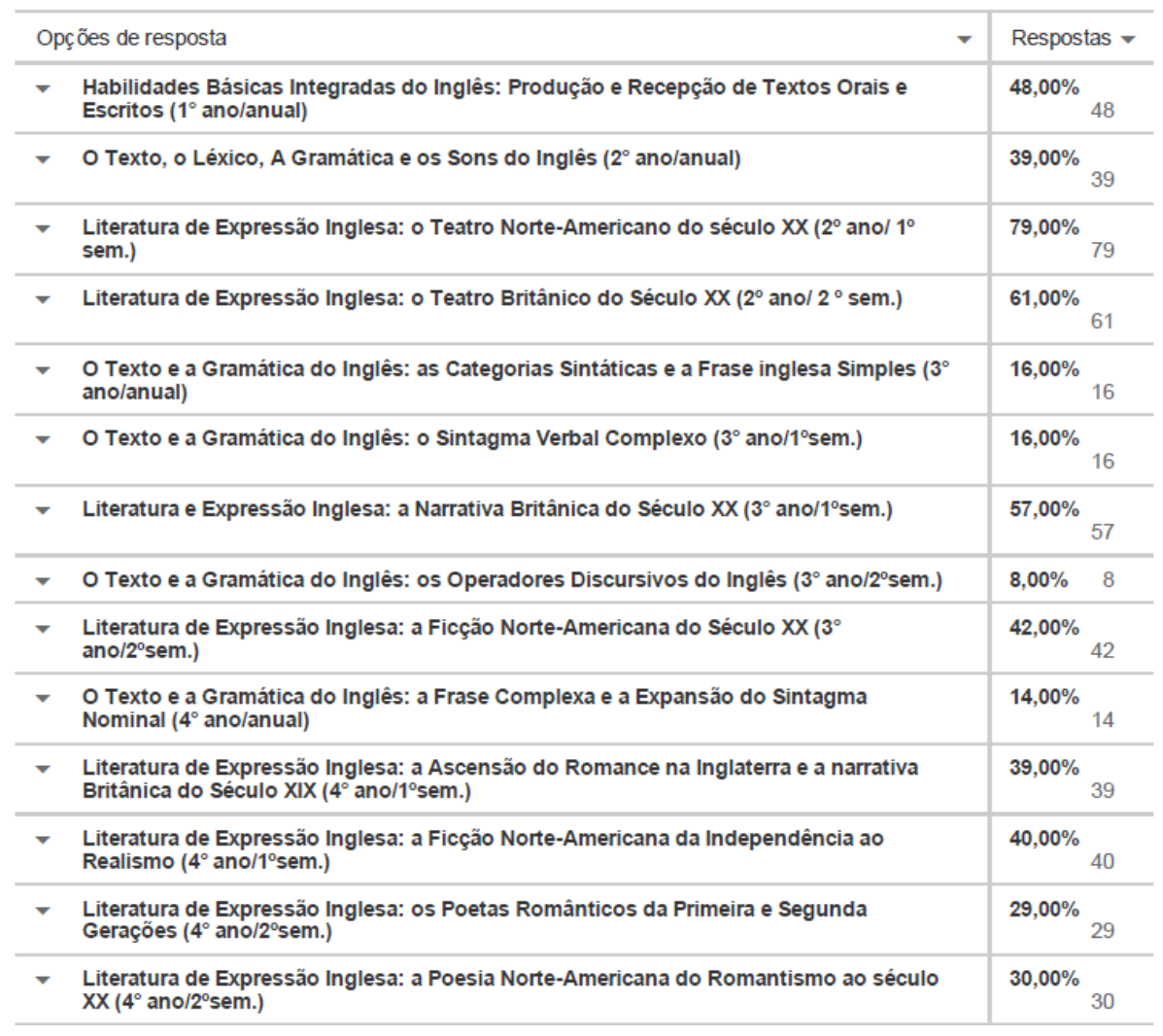

Como se pode ver, as disciplinas de língua inglesa quando comparadas com as disciplinas de literatura foram as que receberam menor número de menções, tendo ficado na maioria das vezes com percentual menor que $20 \%$ nas escolhas dos alunos. Em somente duas

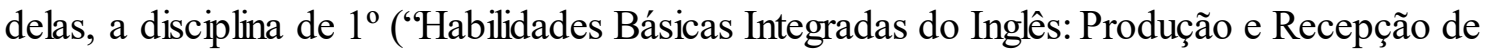
Textos Orais e Escritos") e a de $2^{\circ}$ ano (“O Texto, o Léxico, A Gramática e os Sons do 
Inglês"), o percentual de escolha dos alunos foi um pouco maior, assemelhando-se a maior parte dos resultados das disciplinas de literatura.

Pelo próprio nome das disciplinas de língua, pode-se notar que o foco trazido no programa de ensino é bastante gramatical (o que se comprova na análise dos respectivos programas), mas no caso dessas duas disciplinas especificamente pode ser que o professor tenha inserido alguns conteúdos ligados à temática cultura de tal forma que os alunos a perceberam mais. A alta porcentagem de associação do componente cultural às disciplinas de literatura pode estar ligada à ideia de alta Cultura do cânone literário (KRAMSCH, 2006; MORAN, 2001).

$\mathrm{Na}$ análise do Projeto Político Pedagógico (PPP) do curso de Letras, a palavra cultura aparece 15 vezes, com sentidos ora semelhantes ora distintos. Analisaremos as principais recorrências.

Primeiramente, ela se refere à cultura enquanto grupos sociais, modos de vida e comportamentos, como se pode ver no excerto a seguir:

Uma vez que toda teoria necessita ser continuamente testada e aplicada com vistas à assimilação e, também, que necessita sempre de um corpus sobre o qual possa promover análises, a proposta filosófico-metodológica do Curso de Letras efetiva-se por meio de estudos de culturas específicas, antigas e contemporâneas, analisadas em suas manifestações linguiisticas e literárias, de modo que, enquanto a formação geral fornece as bases mais propriamente abstratas, necessárias para formar um sujeito crítico e capaz de empreender reflexão autônoma sobre a linguagem humana e suas manifestações literárias, as diversas formações específicas garantem a inserção concreta desse sujeito em matérias da mesma natureza, mas comprometidas com uma(s) cultura(s) particular(es), garantindo, ao mesmo tempo, as várias possibilidades de formação proporcionadas pelo Curso de Letras, de modo a proporcionar aos formandos, ao mesmo tempo, os conteúdos necessários para ocuparem as vagas do mercado de trabalho que a sociedade civil requisitar, tendo em vista suas necessidades de atuação profissional. (Projeto Político Pedagógico, p. 4, grifo nosso)

Cultura aqui nos parece vista como civilização (que remete à ideia Iluminista francesa de progresso coletivo da humanidade), ou seja, os grandes feitos de um povo, que se refletem em sua história, instituições sociais, obras de arte, arquitetura, música e literatura, a Cultura. Por outro lado, nota-se também a visão de cultura, com c minúsculo, ainda dentro da perspectiva de civilização, mais associada às práticas cotidianas das pessoas. Ao mencionar culturas específicas e uma(s) cultura(s) particular(es), o PPP parece partir da visão de cultura modernista, de uma comunidade nacional um tanto quanto homogênea com suas instituições, costumes e modo de vida de longa data, enfocando um objetivo utilitarista de "ocupar vagas no mercado de trabalho".

Cultura também aparece associada no projeto político pedagógico a conhecimento, como podemos ver no excerto a seguir.

Uma vez que a tarefa dos cursos de graduação é muito mais formativa do que informativa - não se nega, aqui, a importância da informação como componente de

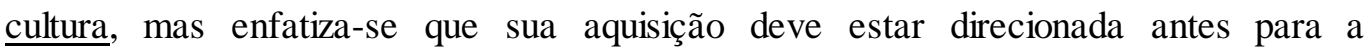
compreensão do que para a mera acumulação de dados. Sua missão é muito mais a de 
levar o aluno a gerir, organizar e compreender informações do que simplesmente fornecê-las, de maneira a suscitar nele uma postura ativa diante do conhecimento. (Projeto Político Pedagógico, p. 6, grifo nosso)

Podemos notar no excerto que cultura é vista como conhecimento, que pode trazer não somente informação, mas também agir como componente de formação do graduando. A palavra aquisição no texto explica o modo como a cultura deverá ser trabalhada e remete à ideia de conhecimento. Ainda nos parece que cultura é vista como um bloco do qual podemos nos apropriar, circunscrita na ideologia do Iluminismo de ideias de progresso, de evolução, de educação, de razão que estavam no centro do pensamento da época.

Ao se pensar a relação entre língua e cultura no ensino de línguas na contemporaneidade, acreditamos na importância de analisar até que ponto nossa prática ainda se baseia na associação de uma língua a uma cultura e vice-versa, fundamentada no conceito de estados nacionais. Muito embora o Estado-nação ainda seja uma entidade de valor político importante, ele não deve ser visto como um ente estável, homogêneo e fechado às influências externas (KUMARAVADIVELU, 2008). Em um mundo no qual as interconexões se acentuaram devido ao aumento da mobilidade das pessoas pelo mundo, assim como pelo contato com outros por meio do uso das novas tecnologias da informação e comunicação, há a necessidade de se entender o componente cultural na aprendizagem de línguas em uma perspectiva discursiva e sociocultural, como um processo constitutivo, construído na interação.

A palavra cultura aparece ainda várias vezes no PPP na expressão "Atividades Acadêmico-Científico-Culturais", é descrita da seguinte forma: "frequência a seminários, eventos científicos, artísticos e culturais, semanas de estudos, e elaboração de uma Monografia de Conclusão de Curso (MCC)". A palavra cultura parece ser entendida aqui do mesmo modo como se apresentou nos primeiros excertos mostrados, ligando-a às artes, literatura, entre outros, uma vez que ela está relacionada à palavra eventos.

As concepções de cultura apresentadas pelos alunos nos questionários parecem espelhar de certo modo algumas daquelas trazidas no PPP, uma vez que muitos deles trouxeram definições de cultura como alta Cultura e também como cultura ligada a costumes e modos de vida. Colocamos na tabela a seguir um levantamento das palavras mais recorrentes ligadas a essas duas definições de cultura nas respostas abertas do questionário à pergunta: Para você, o que é cultura e como ela deve ser abordada no ensino e aprendizagem de língua inglesa?

Tabela 1: Ocorrência de palavras relacionadas à visão modernista de cultura

\begin{tabular}{|c|c|}
\hline Palavra ou expressão & Número de ocorrências \\
\hline língua & 110 \\
\hline costumes & 50 \\
\hline tradição/tradições & 18 \\
\hline povo & 50 \\
\hline grupo social & 8 \\
\hline arte & 20 \\
\hline literatura & 16 \\
\hline história & 13 \\
\hline música & 11 \\
\hline
\end{tabular}




\begin{tabular}{|c|c|}
\hline valores & 9 \\
\hline crenças & 8 \\
\hline hábitos & 7 \\
\hline teatro & 3 \\
\hline
\end{tabular}

Nota-se no quadro que as palavras mais citadas relacionam cultura à visão modernista de civilização e modos de vida (Cultura e cultura). A palavra língua apareceu 110 vezes nos comentários dos alunos, em cerca de $80 \%$ deles. Fica evidente a associação feita entre língua e cultura, já discutida anteriormente.

Em nossa análise dos programas de ensino da grade curricular de língua inglesa, encontramos poucas vezes a ocorrência da palavra cultura ou de alguma menção a estudos que a englobem. As ocorrências são mostradas no quadro a seguir:

Quadro 3: Ocorrência da palavra cultura nos programas de ensino da grade atual de língua inglesa

\begin{tabular}{|l|c|}
\hline Programas de ensino & Ocorrência de referências ao componente cultural \\
\hline Disciplinas de língua inglesa & $\begin{array}{l}\text { Conhecer aspectos socioculturais que contextualizam o uso da } \\
\text { língua. }\end{array}$ \\
& $\begin{array}{l}\text { Textos de informação acadêmica, cultural e enciclopédica e } \\
\text { textos selecionados da literatura de expressão inglesa. }\end{array}$ \\
\hline
\end{tabular}

Como se pode notar, as referências à cultura no que tange às disciplinas de língua inglesa estão relacionadas aos aspectos socioculturais que contextualizam o uso da língua, uma referência clara aos componentes da competência comunicativa. O quadro proposto por Celce-Murcia, Dörnyei e Thurrell (1995), uma das referências até os dias atuais no que tange aos aspectos culturais existentes na competência comunicativa, é bastante abrangente em termos de visão de cultura, abrangendo fatores sociocontextuais, culturais, de adequação estilística e de comunicação não-verbal. ${ }^{2}$ Tal proposta nos parece bastante abrangente, na medida em que traz à tona dentro da competência sociocultural fatores de ordem individual e coletiva, assim como homogeneidades e heterogeneidades presentes em diferentes comunidades. O que nos parece faltar a esse modelo é uma visão que incorpore a dinamicidade da cultura, como constantemente (re)construída nas relações interpessoais e associada a ideologias, atitudes e crenças manipuladas por meio do discurso da mídia, da internet e da indústria do marketing (KRAMSCH, 2011a).

Na grade curricular nova, que ainda entrará em vigor em 2016, há mais ocorrências da palavra cultura nas disciplinas de língua, como se pode ver no quadro a seguir:

\footnotetext{
2 Tratamos mais detalhadamente da concepção de cultura presente no conceito de competência comunicativa no ensino de línguas em Salomão (2011; 2015).
} 
Quadro 4: Ocorrência da palavra cultura nos programas de ensino da grade nova de língua inglesa

\begin{tabular}{|c|c|}
\hline $\begin{array}{l}\text { Programas de ensino da grade } \\
\text { curricular nova }\end{array}$ & Ocorrência de referências ao componente cultural \\
\hline Disciplinas de língua inglesa & $\begin{array}{l}\text { - Conhecer aspectos socioculturais que contextualizam o uso da } \\
\text { língua. } \\
\text { - Textos de informação acadêmica, cultural e enciclopédica e textos } \\
\text { selecionados da literatura de expressão inglesa } \\
\text { - Refletir sobre questões culturais, dando maior ênfase às diferenças } \\
\text { entre a língua materna e estrangeira no que tange a questões de } \\
\text { pronúncia como dificuldades de aprendizagem, inteligibilidade, } \\
\text { variantes e situações de comunicação. } \\
\text { - Tópicos e temas sobre o processo de ensino e aprendizagem para o } \\
\text { desenvolvimento da proficiência escrita: relação língua e cultura da } \\
\text { língua inglesa e língua materna; competência comunicativa, erros e } \\
\text { aprendizagem de línguas, avaliação de línguas estrangeiras. }\end{array}$ \\
\hline $\begin{array}{l}\text { Programas de ensino da grade } \\
\text { curricular nova }\end{array}$ & - Ocorrência de referências ao componente cultural \\
\hline Disciplinas de língua inglesa & $\begin{array}{l}\text { - Identificar os principais momentos histórico-culturais e as } \\
\text { características linguísticas distintas da evolução da língua inglesa } \\
\text { desde seus primórdios até a atualidade, associando as fases mais } \\
\text { importantes de suas transformações com as obras literárias que se } \\
\text { constituem expressão máxima do desenvolvimento do Inglês e } \\
\text { documento singular da riqueza cultural dos povos que a utilizaram } \\
\text { e utilizam como instrumento de comunicação e manifestação } \\
\text { artística em todos os seus aspectos. } \\
\text { - Panorama sucinto da história da língua inglesa e das manifestações } \\
\text { histórico-culturais e linguísticas associadas a ela, em especial a } \\
\text { literatura de expressão inglesa. }\end{array}$ \\
\hline
\end{tabular}

A nova grade parece expandir o conceito de cultura ao trazer à tona a discussão da relação entre língua e cultura, que, a nosso ver, poderia ser tratada a partir das perspectivas sociológica, psicológica ou orientada ao sistema (RISAGER, 2007). Na perspectiva sociológica, explica Risager (2007), a prática linguístico-cultural-discursiva é vista em relação ao macrocontexto cultural. Desse modo, ela pode ser separada do contexto de primeira língua, via migração, por exemplo, e ser transferida para um contexto de uso de segunda língua ou língua estrangeira, o que a levaria a passar por processos de incorporação e mudança. A partir do ângulo sociológico, então, língua e cultura poderiam ser separados. Já em uma perspectiva psicológica, que enfoca não somente a prática, mas sim os recursos linguístico-cultural-discursivos do falante, que são inseparáveis de sua história de vida, teríamos a indissociabilidade de língua e cultura, muito embora suas relações mútuas possam se modificar, se reestruturar ou serem reinterpretadas. Na perspectiva orientada ao sistema, que parte da visão de língua como sistema, teríamos a construção de uma comunidade linguística imaginada ligada a uma construção análoga de uma comunidade cultural imaginada. A conexão entre língua e cultura seria, nesse caso, uma construção ideológica a ser utilizada com propósitos políticos, que poderia, segundo a autora, levar a posições nacionalistas ou ufanistas, mas também poderia defender causas mais legítimas como a preservação de línguas ameaçadas. 
Cremos que cultura na contemporaneidade envolva também uma visão de cultura em fluxo, na perspectiva da pós-modernidade, na qual o estático é substituído pelo dinâmico e noções de "cultura nacional" e o "essencialismo cultural" devem ser repensadas como constituídas de identidades múltiplas - de etnia, gênero, religião, grupo profissional, etc., perpassada por aspectos de ordem coletiva e individual. Desse modo, tratar da temática cultura nas disciplinas de língua inglesa no curso de Letras deve, a nosso ver, fomentar a discussão de questões a respeito de uma problematização dos conceitos de comunicação e cultura no ensino de línguas (THORNE, 2006), envolto no pragmatismo dos encontros interculturais, por meio da construção dialética (KRAMSCH, 1993; 1998; 2006) e do entendimento de cultura como dinâmica e (re)construída na interação, envolta em aspectos de ordem e de interesses individuais e coletivos que perpassam questões sociais, históricas, econômicas e políticas.

A abordagem de cultura não deve ser somente o enfoque de produtos, práticas e perspectivas de um povo, geralmente associado a um estado-nação, numa relação que vai frequentemente da coletividade para o indivíduo e se apresenta na língua como elementos que distinguem esse povo em sua forma de se expressar. Há que se considerar identidade étnica e identidade nacional como entidades conflitantes, evitando tratar os indivíduos como membros de comunidades distintas com características claramente identificáveis, uma vez que existe a possibilidade de os indivíduos desenvolverem identidades, sensos de pertencimento e lealdades múltiplas, algumas das quais podem até mesmo parecer contraditórias (KUMARAVADIVELU, 2008).

Para tal, cremos que alguns conceitos-chave devem ser trabalhados no curso de graduação em Letras, e podem ser trazidos à tona nas aulas de língua inglesa na busca de se associar língua e cultura de forma dinâmica. Ao questionarmos os alunos sobre conceitos relacionados à língua e cultura com os quais estariam familiarizados, notamos que grande parte dos conceitos listados thes era conhecido, seja por experiências no curso ou não (30\% dos alunos afirmaram que o conhecimento era advindo das experiências no curso, $3 \%$ não associaram tal conhecimento ao curso, e $67 \%$ disseram que o curso era parcialmente responsável). A seguir, mostramos a tabela com os conceitos e porcentagens de vezes que foram marcados pelos alunos ao responderem a questão: Com quais dos seguintes conceitos você está familiarizado? 
Gráfico 1: Conceitos conhecidos pelos alunos

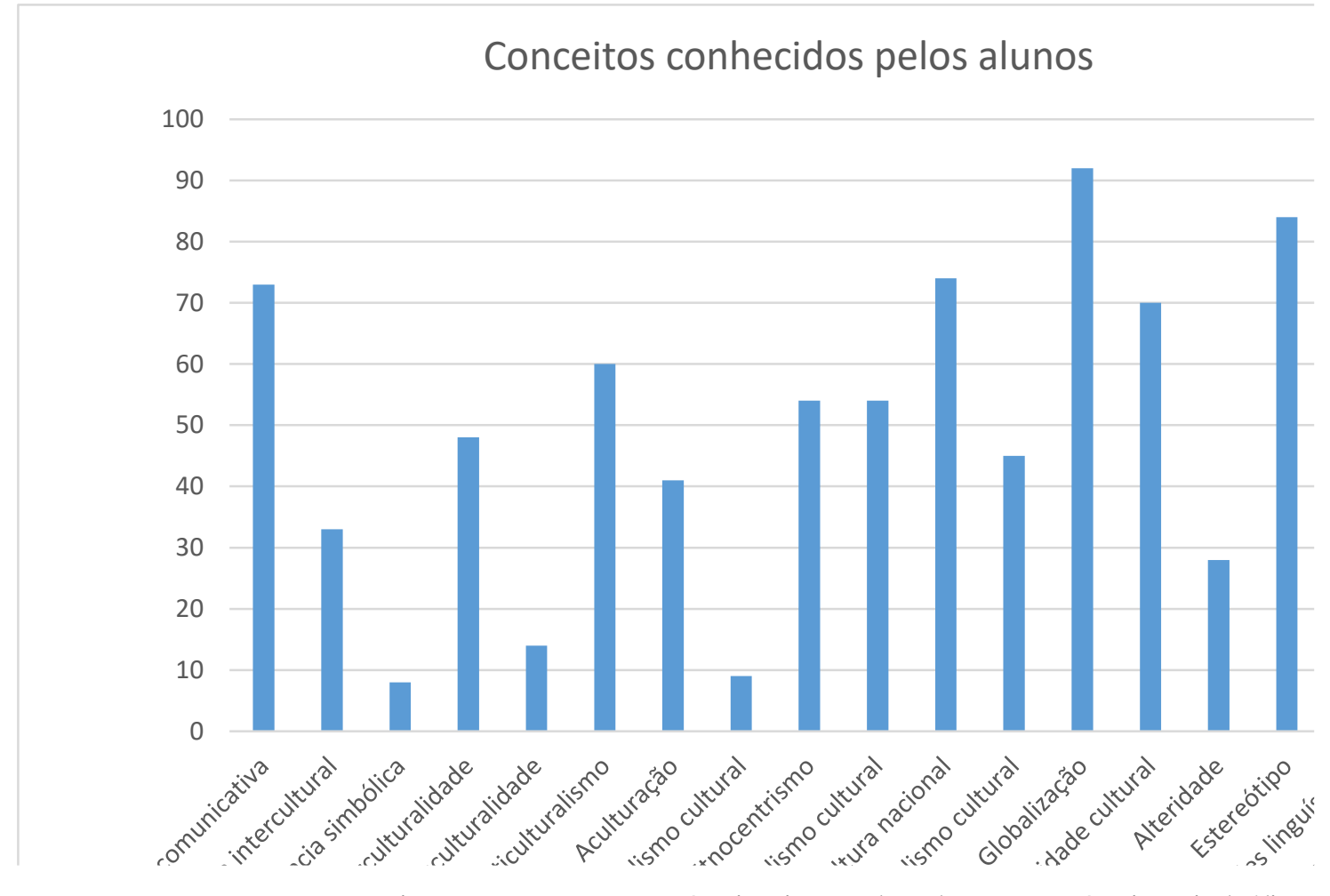

Vemos que conceitos como competência intercultural, competência simbólica, essencialismo cultural e alteridade foram os conceitos menos apontados. Uma vez que a inserção do conceito de cultura na contemporaneidade deve buscar superar concepções que a tratam como conjunto de conhecimentos generalizável, essencialista e homogeneizador, vemos o trabalho com os conceitos citados como essencial para que se possa superar visões de cultura como estanque e transparente, isenta de conflitos e interpretações.

Concordamos com Kramsch (2011a) que cultura é um domínio de comunicação simbólica e o elemento essencial na definição de natureza humana, constituindo-se como a força dominante na história, e compreender cultura significa interpretar tais símbolos de forma situada, no fluxo da ação social. Desse modo, cultura não se apresenta como um sistema coeso, como o que geralmente é estudado de forma disciplinar em cursos de graduação.

\section{Considerações finais}

A área de formação de professores de línguas busca hoje caminhos para realizar a construção de uma identidade profissional do professor de línguas voltada para questões contemporâneas sobre língua, sociedade e cultura, na qual se articulem as reflexões teóricocríticas com os domínios da prática. Cultura na contemporaneidade envolve uma perspectiva que a veja em fluxo, na qual o estático é substituído pelo dinâmico e noções de cultura nacional e o essencialismo cultural devem ser problematizadas como perpassadas por aspectos de ordem coletiva e individual e constituídas de identidades múltiplas (gênero, etnia, religião, grupo profissional, entre outros). 
A abordagem de cultura em sala de aula de língua estrangeira não deve ser somente o enfoque de produtos, práticas e perspectivas de um povo, geralmente associado a um estadonação, numa relação que vai frequentemente da coletividade para o indivíduo e se apresenta na língua como elementos que distinguem esse povo em sua forma de se expressar. Há que se considerar identidade étnica e identidade nacional como entidades conflitantes, evitando tratar os indivíduos como membros de comunidades distintas com características claramente identificáveis, uma vez que existe a possibilidade de os indivíduos desenvolverem identidades, sensos de pertencimento e lealdades múltiplas, algumas das quais podem até mesmo parecer contraditórias.

A questão central seria ir além da noção de busca das diferenças culturais, para tentar adentrar um nível de reflexão no qual se procuraria entender os significados que tais elementos adquirem para determinadas culturas, tanto em nível coletivo (sociedade), quanto em nível individual, transpassados por elementos de identidade multifacetados, compostos de fatores sócio-históricos, políticos e econômicos. Para tal, há que se substituir a visão estática de cultura por uma mais dinâmica, na qual noções de cultura nacional, essencialismo cultural e competência intercultural darão espaço para outras como historicidade, cultura no discurso e cidadania intercultural.

\section{REFERÊNCIAS}

AGAR, M. Language shock: Understanding the culture of conversation. New York: William Morrow and Company, 1994. 284 p.

BAUMAN, Z. A cultura no mundo líquido moderno. Tradução de Carlos Alberto Medeiros. Rio de Janeiro: Zahar, 2013. 111 p.

BYRAM, M; MORGAN, C. Teaching and learning language and culture. U.K.: Multilingual Matters, 1994. $232 \mathrm{p}$.

BYRAM, M. Conceptualizing intercultural (communicative competence and intercultural citizenship). In: JACKSON, J. The Routledge Handbook of Language and Intercultural Communication. New York: Routledge, 2014. p. 85-97.

CELCE-MURCIA, M.; DÖRNYEI, Z; THURRELL, S. A pedagogical framework for communicative competence: a pedagogically motivated model with content specifications. Issues in Applied Linguistics, Los Angeles, v. 6, n. 2, p. 5-35, 1995.

CUCHE. D. A noção de cultura nas ciências sociais. 2. ed. Bauru: EDUSC, 2002. 255 p.

DERVIN, F.; LIDDICOAT, A. J. (Eds.). Linguistics for Intercultural Education. Amsterdam: John Benjamin Books, 2013. 201 p.

DORNYEI, Z. Research Methods in Applied Linguistics. Oxford: Oxford University Press, 2007. $336 \mathrm{p}$.

GUILHERME, M. Critical language and intercultural communication pedagogy. In: JACKSON, J. The Routledge Handbook of Language and Intercultural Communication. NewYork: Routledge, 2014. p. 357-371. 
HALL, S. A identidade cultural na pós-modernidade. Tradução de Tomaz Tadeu da Silva e Guacira Lopes Louro. 11. ed. Rio de Janeiro: DP\&A, 2006. 97 p.

KRAMSCH, C. Context and Culture in Language Teaching. Oxford: Oxford University Press, 1993. 304 p.

. Language and culture. Oxford: Oxford University Press, 1998. 134 p.

Culture in language teaching. In: BROWN, K. (Ed.). Encyclopedia of Language and Linguistics. Vol. 3. 2nd edition. Oxford: Elsevier Science, 2006. p. 322-329.

Cultural perspectives on language learning and teaching. In: KNAPP, K.; SEIDLHOFER, B. (Eds.). Handbook of foreign language communication and learning. Berlin: Mouton de Gruyter, 2009. p. 219-245.

- The symbolic dimensions of the intercultural. Language Teaching, Cambridge University Press, v. 44, p. 354-367, July 2011 a.

Language and culture. In: SIMPSON, J. (Ed.). The Routledge Handbook of Applied Linguistics. New York: Routledge: 2011b. p. 305-317.

KUMARAVADIVELU, B. Cultural Globalization and Language Education. USA: Yale University Press, 2008. 272 p.

MORAN, P. R. Teaching culture: perspectives in practice. Canada: Heinle \& Heinle, 2001. $175 \mathrm{p}$.

RICHARDS, J. C.; RODGERS, T. S. Approaches and Methods in Language Teaching. Cambridge: Cambridge University Press, 1999.

RISAGER, K. Language and Culture: Global Flows and Local Complexity. Clevedon: Multilingual Matters, 2006. 212 p.

Language and Culture Pedagogy: from a national to a transnational paradigm. Clevedon: Multilingual Matters, 2007. 270 p.

SALOMÃO, A. C. B. Vizinhança global ou proximidade imposta? Impactos da comunicação intercultural mediada por computador sobre o papel da cultura no ensino de língua inglesa. D.E.L.T.A., São Paulo, v. 27, n. 2, p. 235-256, 2011.

A cultura e o ensino de língua estrangeira: perspectivas para a formação continuada no projeto Teletandem Brasil. 2012. 270 f. Tese (Doutorado em Estudos Linguísticos) - Instituto de Biociências, Letras e Ciências Exatas, Universidade Estadual Paulista, São José do Rio Preto.

O componente cultural no ensino e aprendizagem de línguas: desenvolvimento histórico e perspectivas na contemporaneidade. Trabalhos em Linguística Aplicada, Campinas, v. 54, n. 2, p. 361-392, 2015.

THORNE, S. L. Pedagogical and Praxiological Lessons from Internet-mediated Intercultural Foreign Language Education Research. In: BELZ, J. A.; THORNE, S. L. (Eds.). AAUSC 2005: Internet-mediated Intercultural Foreign Language Education. Boston: Thomson Heinle, 2006. p. 2-32. 
Recebido em: 02/10/2015

Aprovado em: 14/06/2016 